\title{
Saberes e práticas dos graduandos de enfermagem acercea da violência contra a mulher
}

\author{
|Knowledge and praetiees of undergraduate nursing about violenee against women
}

Conceiţão de Maria Vaz Elias ${ }^{1}$

\section{Resumo}

$O$ estudo objetivou analisar os saberes e práticas dos acadêmicos de enfermagem acerca da violência contra a mulher no contexto de sua formação acadêmica. Trata-se de estudo descritivo, de abordagem qualitativa, utilizando técnica de produção de dados, a entrevista foi realizada com 15 acadêmicos de enfermagem, matriculados no último periodo do curso. Como resultado foi observado, que os sujeitos do estudo, em sua maioria são do sexo feminino, solteiros, consideram-se católicos, com média de idade de 21 e 36 anos. Foram agrupadas três categorias de análise, quais sejam: conhecimentos atuais acerca da violência contra mulher, formação acadêmica frente à violência $e$ condutas dos graduandos frente à violência. Concluiu-se há pouco conhecimento dos acadêmicos de enfermagem sobre fenômeno, e cujas informações são generalizadas e sem uma reflexão mais concreta sobre a temática, inclusive sobre as políticas de enfrentamento e ações de enfermagem. Assim, os órgãos formadores necessitaria adequar as seus currículos, e haver uma maior inserção da temática.

\section{Abstraet}

The study it objectified to analyze the knowledge and practices of nursing students about violence against women in the context of their academic training. This is a descriptive study with a qualitative approach, using technical production data, the interview was conducted with 15 nursing students enrolled in the final period of the course. As result was observed that the subjects of the study are mostly female, unmarried sex, consider themselves Catholics, with an average age of 21 and 36 years. Three categories of analysis were grouped, namely: current knowledge about violence against women, violence against the academic training of undergraduates and conduct towards violence. Concluded that there is little knowledge of nursing students about the phenomenon, and whose information is generalized and without a more concrete reflection on the topic, including on policies to fight and nursing actions. Thus forming organs require tailor their resumes, and be a greater integration of the theme.

\section{'Centro Universitário UnINOVAFAPI}

Para correspondência:

Conceição de Maria Vaz Elias

E-mail: conceicaovazenf@hotmail.com
Data da Submissão:23/06/2014 Data do Aceite: 23/06/2014 
Introducã̃o

Violência é um fenômeno conhecido em todo o mundo, e é motivo de grande preocupação pela quantidade de vítimas acometida. A violência contra as mulheres constitui-se em uma das principais formas de violação dos seus direitos humanos, atingindo-as em seus direitos à vida, à saúde e à integridade física. Em todas as suas formas (doméstica, psicológica, física, moral, patrimonial, sexual, tráfico de mulheres, assédio sexual, etc.) poderá acometer mulheres de diferentes classes sociais, origens, idades, regiões, estados civis, escolaridade, raças e até mesmo a orientação sexual (1).

O drama da violência está no cotidiano das cidades, do país e do mundo, e é ainda banalizado e percebido pela sociedade como algo que natural. Estima-se que a violência praticada contra mulheres de 15 aos 44 anos, seja responsável por mais mortes que o câncer, a malária, os acidentes de trânsito e as guerras (2).E isso por ser tratado como problema de saúde pública, deve ser bem tralhado na formação dos acadêmicos, e ser abordado mais vezes pelos profissionais da área.

Estudos revelam que os profissionais de saúde, inclusive os enfermeiros, possuem dificuldades para cuidar das vítimas de violência, e estas podem estar relacionadas com a formação acadêmica, na qual carecem de assuntos com produção de conhecimento técnico e específico sobre o tema violência ${ }^{(3)}$.

Visto que, o enfrentamento da violência contra as mulheres é um fenômeno destrutivo da vida e saúde. Torna-se fundamental que os serviços de saúde, a população e profissionais de saúde, passem a se preocupar com tais dimensões, procurando identificar e compreender o fenômeno da violência em profundidade, para enfrentá-lo de forma a superar o modo intervencionista, ainda hegemônico, que reproduz a ideologia opressora dominante. Evidencia-se ainda, a responsabilidade dos órgãos formadores no preparo de futuros profissionais, de compreender essa questão no âmbito da saúde e reconhecer seu papel social na identificação e assistência articulada nas situações de violência contra as mulheres ${ }^{(4)}$.

$O$ cuidar que a enfermagem deve proporcionar, às vítimas de violência, precisa ser planejado com intuito de promover acolhimento, segurança, respeito e satisfação das suas necessidades individuais. Assim, é fundamental, haver uma reflexão acerca do seu planejamento, pautado em instrumentos básicos de enfermagem, nas políticas públicas de saúde e na legislação vigente, que é fundamental para a proteção das vítimas e prevenção de futuros agravos $^{(5)}$. Os graduandos de Enfermagem devem ser bem orientados, para identificação de manifestações de violência, condução e enfrentamento.

A vivência de violência contra a mulher é um fenômeno social que influencia o modo de viver, adoecer e morrer das mulheres,é necessário se faz a construção de saberes e práticas, que favoreçam o cuidado à mulher em situação de violência. Os resultados ainda poderão auxiliar numa tomada de decisão para ampliar estratégias que possam contribuir para melhoria das condutas desses acadêmicos( ${ }^{(6)}$.

Assim, este estudo objetivou analisar saberes e praticas dos graduandos de enfermagem acerca da violência contra a mulher,no contexto de sua formação acadêmica.

\section{Metodologia}

Trata-se de um estudo descritivo, com abordagem qualitativa, voltado para a percepção,à intuição e a subjetividade dos participantes sobre violência contra mulher. Essa abordagem trabalha com dados não quantificáveis, estuda os sentimentos que não pode ser tratado em números, fenômenos voltados para a percepção, à intuição e a subjetividade. Nesse sentido, buscar-se-á a compreensão das respostas dadas pelos sujeitos investigados, as quais refletem a realidade $\operatorname{vivida}^{(7)}$.

Os dados foram coletados no mês de maio de 2012, e as entrevistas foram realizadas com 15 acadêmicos de enfermagem, matriculados no último período do curso (critério de inclusão) de uma Instituição de Ensino Superior-IES privada do município de Teresina, Piauí, Brasil. A participação foi voluntária mediante leitura e assinatura do Termo Consentimento Livre e Esclarecido- TCLE. Para garantir sigilo e anonimato dos entrevistados os mesmos foram identificados por (Dep.) significando depoente com numeração sequenciada.

Aanálise de dados foi através da técnica de análise de conteúdo, dando um significado amplo e conjugando com os conhecimentos 
adquiridos ao longo do estudo, respondendo aos objetivos propostos. A técnica de análise de dados possui três fases. Na pré-análise que é a fase da organização, podendo adotar como procedimentos a leitura que se fundamenta na interpretação, observando a frequência absoluta e relativa dos dados coletados, privilegiando o sentido global dos discursos. A segunda fase seria a exploração do material, onde os dados serão codificados a partir das unidades. $\mathrm{O}$ passo seguinte, terceira fase, consiste na construção de categorias, que é uma operação de classificação de elementos constitutivos de um conjunto, por diferenciação e, seguidamente por reagrupamento, em função de características comuns ${ }^{(8)}$.

O trabalho foi aprovado pelo Comitê de Ética e Pesquisa com parecer CAAE: 09075912.6.0000.5210.

\section{Resultados e Diseussão}

Participaram do estudo, quinze sujeitos, tais participantes possuem características similares em relação aos dados sócio demográficos, sendo treze do sexo feminino e dois do sexo masculino, com faixa etária entre de 21 e 36 anos. Em relação ao estado civil, doze participantes eram solteiros e apenas três casados. No que se refere à religião, quatorze são católicos e um espírita. Para compor os resultados, analisaram-se os discursos, no qual foi possívelextrair três categorias: Conhecimentos atuais acerca da violência contra mulher; Formação acadêmica frente à violência e Condutas dos graduandos frente à violência.

\section{Conhecimentos atuais acerea da violência contra mulher}

A violência contra a mulher não é algo referente aos dias atuais. Porém, tem tido maior destaque, na atualidade, tanto pela autonomia das mulheres, globalização das denuncias, e o reconhecimento da violência, como um crime. Nesta categoria os acadêmicos revelam seus saberes acerca da violência contra mulher, assumindo que esta, poderá ser, psíquica, verbal, sexual ou psicológica.

Nos depoimentos abaixo, percebe-se que há um conhecimento bem esclarecido acerca, das formas que esse fenômeno se manifesta e relatam também a sua magnitude atualmente:
"A cada dia aumenta o numero de mulheres que são violentadas. A violência não é só física existe também a violência psíquica, a verbal,sexual (Dep. 01).

"A cada um minuto uma mulher é violentada no Brasil. $O$ alto indice de violentadas anualmente são dados alarmantes." (Dep. 03).

"É qualquer violência que seja expressamente direcionada a mulher, como física, verbal, psicológica, repressiva, etc" (Dep.12.).

"A violência não é só física, mas também psicológica obrigar a mulher fazer atos que a mesma não deseja, dizer palavras que denigrem sua imagem, bater, acusar, usurpar, humilhar [...]" (Dep. 09).

Revelam também, que a principal vítima dessas violências, são as mulheres de baixas condições financeiras, e é o principal motivo que predispõe a violência. E o praticante da violência, em sua maioria são seus companheiros. Estes sujeitos devem fundamenta-se pelo fato dos homens a décadas terem tido o papel ativo na sociedade, sendo o que trabalha cabendo à mulher o papel de reprodutora, dependendo financeiramente e cuidado dos filhos.

É o que se pode perceber nas falas:

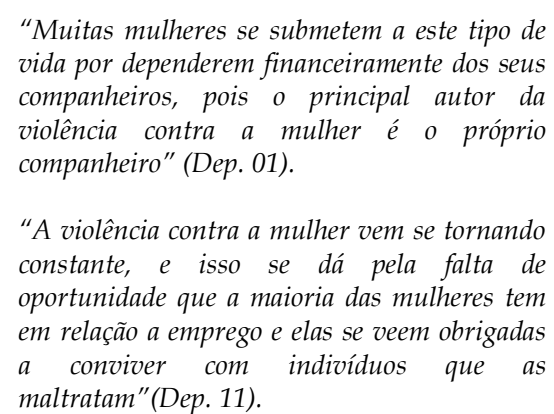

Pesquisas apontam que as mulheres são alvos de todo tipo de violência e que na maioria dos casos, é provocada por parentes ou pessoas próximas a vítima. E que a dependência emocional, configura-se como agravante para as mulheres, permanecendo na convivência com tal prática $^{(9)}$.

A dependência econômicaque se tem pelo companheiro, também vem sendo apontada como motivo para as mulheres continuarem na relação principalmente quando possuem filhos. Essas mulheres ficam preocupadas, com a sua subsistência edas crianças, e com a punição legal do agressor o afastará de suas atividades laborais, o que comprometerá a renda familiar, sendo assim, essas mulheres optam pelo silêncio( ${ }^{(10)}$. 
Quando questionados sobre o que sabem sobre violência contra mulher, a maioria dos sujeitosmostrou estar ciente da existência da Lei Maria da Penha, que é tipicamente bastante divulgada nos meios de comunicação, como demonstra as falas:

\footnotetext{
"Nos últimos anos, graça ao trabalho realizado pelos governantes criaram a Delegacia contra violência a mulher, com a lei que pune quem maltrata a mulher"(Dep.13).

"Hoje a mulher já conta com uma lei especifica, para estes casos de agressões, é a Lei Maria da Penha"(Dep. 02).

"A violência contra a mulher infelizmente, ainda é um grande problema social, mas que tem melhorado muito com a Lei Maria da Penha, às mulheres estão denunciando mais os companheiros" (Dep. 08).
}

No Brasil a violência contra a mulher é crime. Na sua história, o país, tem muitas mulheres que tiveram suas vidas associadas a esse fenômeno. Decorrente de denúncias houve a conquista da Lei Maria da Penha, que visa reduzir a ocorrência do fenômeno, punir os agressores e que se constitui como um dos instrumentos de proteção social à mulher. Essa Lei, com o número 11.340, entrou em vigor a partir de 22 de outubro de 2006. No artigo 44, determina pena de detenção para o agressor, de três meses a três $\operatorname{anos}^{(11)}$.

\section{Forma६̧ão acadêmi६̧ frente à violência}

Ao questionar como a temática sobre a violência contra a mulher foi abordada durante o curso de Enfermagem, percebe-se que dentre os depoimentos houve muita divergência, uma parte afirmaram que a temática foi abordada de forma suficiente, clara e por vários mecanismos: seminários, aulas e palestras. Já outra parte afirma que o tema foi abordado de forma sucinta. Como é evidenciado nas falas a seguir:

\footnotetext{
"Foi abordada de forma clara, porém não focou muito essa temática"(Dep.7).

"Foi abordado de uma forma ampla e direcionado ao assunto. Atingiu os objetivos e fez com que refletíssemos mais sobre o assunto" (Dep. 3).

"Foi abordado de maneira ampla, esclarecedora onde foi tirado as dúvidas, sobre a violência e como a mulher procurar ajudar" (Dep. 14).

"Foi visto sim mais muito rápido" (Dep.10).

"Como muitas temáticas, a violência contra a mulher também foi vista de forma muito
}

sucinta" (Dep.11).

Na luz deste contexto observa-se que os acadêmicos, durante a formação, entraram em contato com essa temática apenas de forma teórica, sem nenhuma aplicação prática. Essa lacuna na formação refletirá futuramente no dia a dia desses acadêmicosnos serviços de saúde. Algumas falas dos sujeitos mostram essa questão:

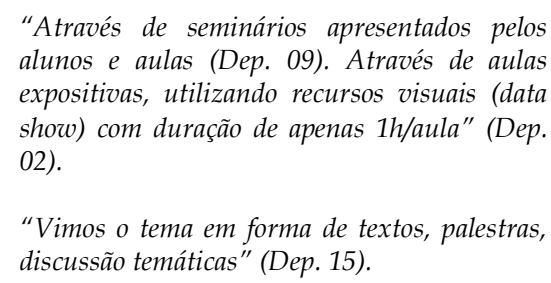
alunos e aulas (Dep. 09). Através de aulas expositivas, utilizando recursos visuais (data show) com duração de apenas 1h/aula" (Dep. 02).

"Vimos o tema em forma de textos, palestras, discussão temáticas" (Dep. 15).

Tais acadêmicos, ao se depararem, com essa situação, terão dificuldades para lidar com as questões associadas à violência contra a mulher. Com capacitação insuficiente, para o enfrentamento da questão e com dificuldades a quem recorrer nos momentos de dificuldade.

Em se tratando do momento em que o tema foi abordada, a maioria dos estudantes revelaram que foram na disciplina de Saúde da Mulher. Houve também menção de outras disciplinas, como Saúde Pública, Deodontologia, Saúde da Criança, Saúde e Sociedade e Educação em Saúde. E apenas, um dos sujeitos, não lembrou em qual disciplina havia sido abordado à temática. Como é observado nas frasesa seguir:

\footnotetext{
"Este assunto foi abordado na disciplina Saúde da Mulher, que faz parte do $5^{\circ}$ período do curso"(Dep. 02).

"A violência contra mulher foi abordada durante o curso quando pegamos a disciplina Saúde da Mulher inicialmente, depois em Educação em Saúde" (Dep. 08).

"Foi comentada em diversas disciplinas como Saúde da Mulher, Deontologia, e ainda em Saúde da Criança, quando a violência sofrida pela mãe que ocorre na presença das famílias e em outras disciplinas" (Dep. 15).
}

Entretanto, poucas disciplinas do curso de Enfermagem incluem o ensino sobre violência contra mulher e quando abordam esse tema, às vezes, é de maneira superficial, necessitando o aluno mais tarde buscar soluções que minimizam as lacunas de seu aprendizado, sobre o fenômeno, atrás de futuras atualizações, aperfeiçoamentos e especializações.

Os órgãos formadores, ainda intuem 
pouco o tema como pertinente ao âmbito da saúde desconhecem a sua magnitude e, consequentemente, não o priorizam como um problema a ser incorporado nos planejamentos curriculares de seus cursos. Por outro lado, parece não haver uma integração entre as políticas existentes e preconizadas pelo Ministério da Saúde quanto à formação dos profissionais da saúde e esses órgãos formadores(12).

Considerou-se que o conhecimento, dos acadêmicos de Enfermagem, geral e este associou tal violência ao gênero, classe, e em nenhum momento comentaram acerca da Política Nacional de Enfrentamento à Violência contra as mulheres, e sobre a rede intersetorial, reproduzindo em sua maioria conceitos fragmentados e de senso comum.

\section{Condutas dos graduandos frente à violêneia}

Dessa categoria emergiram depoimentos sobre atuação, como acadêmicos, frente ao cliente que esteja passando por situações de violência. Estes sujeitos remeteram as principais práticas: utilização da equipe multiprofissional (médico, psicólogo, assistente social) e orientações em buscar outros setores para denunciar o agressor.

Quanto à primeira atuação dos acadêmicos, sugere-seque esta se relaciona com um acompanhamento de Enfermagem individualizado e fragmentado, pois, as vítimas de violência, são encaminhadas ao psicólogo, médico e assistente social. Como é revelado nas falas a seguir:

\footnotetext{
"Encaminharia esta paciente para profissional especializado de acordo com a necessidade da mulher por exemplo, psicológico" (Dep. 01).

"Procuraria ajuda do médico, psicólogo e assistente social, para que esta pessoa receba um atendimento multidisciplinar" (Dep. 04). "Apoia-la, encaminhar para psicólogo se for necessário" (Dep. 06).
}

Contudo, para que haja a superação da violência, a perspectiva que deve ser adotada é a de integração intersetorial, atenção integral, interdisciplinar, os serviços devem estar pautados em trabalho de equipes com desempenho multiprofissional. E não apenas no interior de cada serviço, mas entre os serviços de um mesmo setor de assistência, assim como entre distintos setores que prestam assistência às mulheres em situação de violência, espera-se que trabalho se dê de modo interligado(13).

A segunda prática evidenciada, referente os casos de violência, é em fazer orientações à busca de serviços intersetoriais, como Conselho Tutelar, delegacias, como e notado nos casos a seguir:

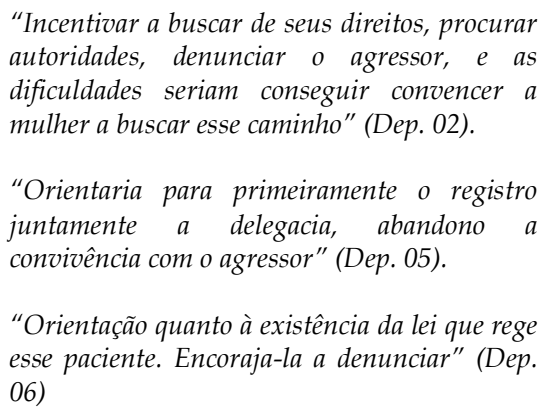

"Incentivar a buscar de seus direitos, procurar autoridades, denunciar o agressor, $e$ as dificuldades seriam conseguir convencer a mulher a buscar esse caminho" (Dep. 02).

“Orientaria para primeiramente o registro juntamente a delegacia, abandono a convivência com o agressor" (Dep. 05).

"Orientação quanto à existência da lei que rege esse paciente. Encoraja-la a denunciar" (Dep. 06)

Ao realizar o planejamento este deve alcançar todos os setores e âmbitos de um sistema, de uma maneira que todos saibam suas responsabilidades e funções, e em que todos conheçam as interseções, interfaces e compartilhamentos, ao mesmo tempo. Dessa forma, qualquer ação realizada visará dar apoio e suporte às famílias vítimas de violência, buscando transformar a realidade objetiva quando utilizado de modo satisfatório a intersetorialidade como uma ferramenta para extinguir a violência contra a mulher(14).

Outra atuação acadêmica evidenciada nos discursos, entretanto em casos isolados, foi sobre a notificação da violência. O Protocolo de Notificação Compulsória de identificação ou suspeita de violência contra crianças e mulheres em todos os serviços no âmbito do SistemaÚnico de Saúde, é alguns dos importantes avanços podem ser observados na atenção às vítimas de violência, que foi instituído em 2004(15). Com o intuito do poder público, elaborarestratégias de controle da violência contra a mulher, evitando deixar agressores impunes e ampliando agravantes para os reincidentes, entretanto, a notificação não consiste em medida de enfrentamento, e sim apenas, como meio de formação de banco de dados sobre violência.

O conhecimento dessa temática é importante, pois os serviços de saúde em geral, é a primeira escolha das vítimas, e os profissionais estão em contato direto. Então, estes devem ser profissionais de saúde, atentos a estas mulheres que procuram os serviços observando os sinais da violência e manifestações físicas, mentais, sociais dentre outras. Estabelecer privacidade da vítima é 
importante, bem como, um ambiente de confiança, e desconstruir mitos e preconceitos, com orientações sobre a violência como um todo.

Não existe um modelo para cuidar, porém acadêmicos melhor preparados terão melhores condições de reduzir os índices destes agravos e mudar a realidade social. Contudo, o Ministério da Saúde, através das políticas de saúde, trás direcionamentos quanto à prática profissional, necessitando que esta seja ser detectada precocemente com prevenção de agravos futuros.

\section{Conelusão}

Evidenciou-se pouco conhecimento dos acadêmicos de Enfermagem, acerca da violência contra mulher, cujas informações são generalizadas e sem uma reflexão mais concreta sobre a temática, inclusive sobre as políticas de enfrentamento e ações de Enfermagem. Diante desse panorama, os órgãos formadores necessitaria adequar as seus currículos, e haver uma maior inserção da temática, tanto praticateórica, como em extensões e pesquisas cientificas.

Assim, as mudanças não podem acontecer apenas nos serviços de saúde, deve ocorrer ao longo prazo nas instituições que formam os acadêmicos. Para que o aluno mais tarde não precise buscar exclusivamente soluções que minimizam as lacunas de seu aprendizado, sobre o fenômeno.

É preciso que órgãos formadores, percebammais a temática como pertinentes ao âmbito da saúde, e conhecer a sua importância, e consequentemente prioriza-la em seus planejamentos curriculares de seus cursos. O conhecimento acerca da violência contra mulher e as condutas adotadas pelos acadêmicos de Enfermagem, necessitam ser orientadas durante a graduação para melhor condução e enfrentamento desse problema e ações.

Tal estudo torna-se relevante, para os profissionais de saúde, em especial a Enfermagem, que estão em contato direto com a maioria das vítimas, pois é nos serviços de saúde que normalmente buscam ajuda e tratamento. E para reduzir tais agravos, esses profissionais necessitamreconhecer a violência, cuidar das vítimas de forma eficaz, necessitando assim, ser capacitados para tal.
1. Ministério da Saúde (BR). Secretaria de Políticas para as Mulheres. Pacto Nacional pelo Enfrentamento à Violência contra a Mulher. Coleção enfrentamento à violência contra as mulheres. Brasília: Ministério da Saúde; 2011. [Acessado 28 Maio 2012]. Disponível em: http://www.sepm.gov.br/publicacoesteste/publicacoes/2011/politica-nacional

2. Schraiber LB. Violência dói e não é direito: a violência contra a mulher, a saúde e os direitos humanos. São Paulo: Editora UNESP; 2005.

3. Faúndes A, Rosas CF, Bedone AJ, Orozco LT. Violência sexual: procedimentos indicados e seus resultados no atendimento de urgência de mulheres vítimas de estupro. RevBrasGinecol Obstet. 2006;28(2):126-35.

4. Vieira LB, Padoin SMM, LanderdahlMC. A percepção de profissionais da saúde de um hospital sobre a violência contra as mulheres. Rev. Gaúcha Enferm. (Online) . 2009Dec ; 30(4): 609-616. [Acessado 28 Maio 2012]. Disponível em: http://www.scielo.br/scielo.php?script=sci_arttext \&pid=S1983-

$14472009000400005 \& \operatorname{lng}=$ en\&nrm=isoaccess

5. Ferraz MIR, Lacerda MR, Labronici L M, Maftum MA, Raimondo ML. O cuidado de enfermagem a vítimas de violência doméstica. Cogitareenferm. . 2009;14(4): 755-759. [Acessado 29 Ago. 2013]. Disponível em: http://ojs.c3sl.ufpr.br/ojs2/index.php/cogitare/art icle/view/16395/10874

6. Guedes RN, Silva ATMC, Fonseca RMGS. A violência de gênero e o processo saúde-doença das mulheres. Esc Anna Nery RevEnferm. 2009; 13(3):625-31

7. Figueiredo, NMA. Método e Metodologia na pesquisa científica. 3 ed. São Caetano do Sul: Yendis Editora; 2008.

8. Bardin L. Analise de Conteúdo. Trad: Luís Antero Romero, Augusto Pinheiro, São Paulo: Edições 70; 2011

9. Pereira GN, Lorenzini EA, Brock CJ, do Nascimento PGP, Araujo SSJ, Bettinelli LA. Profissionais de saúde significando a permanência da mulher na relação de violência conjugal. Revista da Rede de Enfermagem do Nordeste 201314558-567. [Acessado 4 de Fev.2013]. Disponível em: http:/ / www.redalyc.org/articulo.oa?id=3240279910 12

10. Jong LC, Sadala MLA, Tanka ACA. Giving up reporting the aggressor: reports of female victims of domestic violence Rev Esc Enferm USP. 2008; 42(4):744-51.

11. Lei $\mathrm{n}^{\circ}$ 11.340, de 7 de agosto de 2006. Cria mecanismos para coibir a violência doméstica e familiar contra a mulher, nos termos do $\S 8^{\circ}$ do art. 226 da Constituição Federal, da Convenção sobre a Eliminação de todas as formas de discriminação contra as mulheres e da Convenção Interamericana para prevenir, punir e erradicar a violência contra a mulher; dispõe sobre a criação dos Juizados de Violência Doméstica e Familiar contra a Mulher; altera o Código de Processo Penal, o Código Penal e 
a Lei de Execução Penal; e dá outras providências. Brasília: DOFC, no 000001, Seção 1, 08 ago. 2006.

12. Edinilsa RS, Ana Lúcia F, Neuci CS. Concepções de docentes em relação ao manual sobre violência intrafamiliar. Revista Brasileira de Educação Médica. 2009; 33(3): 329-338.

13. Schraiber LB, Pires Lucas d'Oliveira AF, Hanada H, Kiss L. Assistência a mulheres em situação de violência - da trama de serviços à rede intersetorial. Athenea Digital. Revista de Pensamiento e Investigación Social 2012; 12237-254.

14. Salcedo-Barrientos DM, Gonçalves L, Oliveira Junior M, Egry EY. Violência doméstica e enfermagem: da percepção do fenômeno à realidade cotidiana. av.enferm. [serial on the Internet]. 2011Dec; 29(2): 353-362.

15. Villela WV,Vianna LAC, Lima LFP, Sala DCP, Vieira $\mathrm{TF}$, Vieira ML et al. Ambiguidades e contradições no atendimento de mulheres que sofrem violência. Saude soc.[serial onthe Internet]. 2011Mar; 20(1): 113-123. 